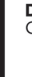

DE GRUYter DO: 10.1515/plass-2015-0032

T. O. Kehinde*, M. A. Adebisi, A. O. Alegiledoye, O. O. Ajani, K. A. Shofuyi

Department of Plant Breeding and Seed Technology, Federal University of Agriculture,

Abeokuta, P. M. B. 2240, Abeokuta, Ogun State, Nigeria,

Corresponding Author e-mail: kehindeto@funaab.edu.ng, adekolaitan@yahoo.com

\section{EVALUATION OF SEED NUT SIZE AS INDEX OF SELECTION FOR SUPERIOR SEED QUALITY ATTRIBUTES IN TWO BIOTYPES OF CASHEW \\ (ANACARDIUM OCCIDENTALE)}

\begin{abstract}
Quality seed nuts are germane to propagation of the cashew plant. Seed nut fraction and genotypes have been identified to influence seed quality of crop plant. Unexpectedly, seed size effect has not been well documented in Brazilian and local biotypes of cashew grown in Nigeria. An experiment was initiated to investigate the effect of three nut sizes and two biotypes of cashew on seed quality (physical and physiological) traits. Seed nut were collected from three cashew plants of the same age of each of the biotypes and were allowed to stay for 60 days after collection. The experiment was carried out in a factorial arrangement laid out in a completely randomized design with three replicates using two factors (nut size and biotypes) in 2011 cropping season in both laboratory and screen house tests. Data were collected on physical characters such as seed length, seed width, 100 seed weight and seed imbibition rate while physiological characters were seed germination and early vigour traits. Data obtained were analysed statistically using Tukey HSD test at 5\% probability level. The result revealed that some of the characters were significantly different from one another. Seed nut fraction and biotype had considerable effect on seed length, seed width, seed imbibition rate and 100 seed weight. The two factors (nut size and biotype) interaction had profound effect on seed width only. On seed physiological quality, biotype effect was significant on seedling fresh and dry weights and seedling growth rate whereas seed nut size had considerable effect on seed germination, seedling vigour index, seedling fresh weight and seedling growth rate. The interaction effect of nut size and biotype recorded significant effect on the above four characters. Brazilian biotype had superior physical characters (seed length, width and weight) but with low imbibitions rate while medium and large nut sizes gave the highest seed germination and seedling vigour. Also, medium and large nuts had the highest seedling fresh weight whereas the highest seedling growth rate was recorded with small size seed. However, large, medium and small nut sizes of local biotype had the highest imbibition rate, whereas small, medium and large nut size of Brazilian biotype gave the highest 100 seed weight. On seedling emergence, large nuts of local biotype recorded the highest seedling emergence and seedling vigour index. Medium nuts of the two biotypes of cashew are recommended for cashew seed multiplication. Further research on physiology of cashew nut sizes during storage and osmo and hydro priming treatment effect are necessary and therefore advocated.
\end{abstract}

Keywords: cashew, seed vigour, emergence, seed nut size

Communicated by Grzegorz Żurek 


\section{INTRODUCTION}

The cashew (Anacardium occidentale) is a member of family Anacardiaceae, Genus Anacardium. Cashew is a native to Brazil and was distributed round the world by Portuguese explorer in the 1500's. The cashew tree is now found throughout the tropical world and in some subtropical areas with favourable conditions. Its economic importance lies in the commercial value of the kernel extracted from the fruit. The most important producing countries are Vietnam, India, Brazil, Nigeria and Tanzania. Collectively, these countries account for $78 \%$ of the world production (FAO, 2004).

The cashew tree grows with a minimum of attention and is easily cultivated. It is usually found from sea level to an altitude of 1000 meters (3000 feed), in regions with annual rainfall as low as $500 \mathrm{~mm}$ (20 inches) and as high as $3750 \mathrm{~mm}$ (150 inches). For maximum productivity, good soil and adequate moisture are essential. Optimum conditions include an annual rainfall of at least $889 \mathrm{~mm}$ (35 inches) and not more than 3048mm (120 inches) (Subbaiah, 1982). The tree has an extensive root system, which helps it to tolerate a wide range of moisture levels and soil types, but commercial production is only advisable in well-drained, sandy loam or red soils. The cashew tree can flourish in the sand of open beaches, but it grows poorly in heavy clay or limestone.

Most cashew trees start bearing fruit in the third or fourth year, and are likely to reach their mature yield by the seventh year if conditions are favourable (Subbaiah, 1982). The average yield of nuts of a mature tree is in the range of 7$11 \mathrm{~kg}$ per annum. Although the cashew tree is capable of living for 50-60 years, most trees produce nuts for about 15-20 years (Subbaiah, 1982).

Seed nuts are vital to the propagation of the cashew plant (Udoh, 2005; FAO, 2007). In Nigeria, these are usually obtained from current season harvest, sun dried and sorted under ambient temperature before growing. Unexpectedly, seed size effects have not been fully documented in Brazilian and local varieties of cashew grown in Nigeria. If the effects are found, it helps to ensure the proper maintenance of seed nuts in cashew after harvest. The study was investigated to examine the relative influence of fruit nut size and after nut harvest on seed physical characteristics and physiological quality of two varieties of cashew and to determine the extent of relationships between fruit nut and size and seed physical characteristics and physiological quality of cashew.

\section{MATERIALS AND METHODS}

\section{Seed Source}

Fruit nuts were obtained from cashew plantation of the Federal University of Agriculture, Abeokuta (FUNAAB) (Latitude $7.10^{\circ} \mathrm{N}$ and longitude $3.2^{\circ} \mathrm{E}$ ), Ogun State, South Western Nigeria. The fresh nut seeds were harvested from the two cashew plant varieties (Brazilian and local biotype) and were obtained 
during the fruiting season, February- March, 2011. The nuts were dried for 40 days after collection under laboratory conditions $\left(30^{\circ} \mathrm{C}, 70 \% \mathrm{RH}\right)$.

\section{Seed nut sizes estimation}

Cashew seed nuts were visually graded according to size into large, medium and small. The seed nuts were weighed and classified into category depending on the size with nut sizes ranging from 8-11.9 $\mathrm{g} \times$ nut $^{-1}$ for large nuts, while medium seeds ranged from 4-7.9 $\mathrm{g} \times$ nut $^{-1}$ and small nuts from 2-3.9 $\mathrm{g} \times$ nut $^{-1}$.

\section{Soil collection and poly bags filling}

Top soils $5-9 \mathrm{~cm}$ depth were collected from fallow farm land of the Teaching and Research Farm Unit, FUNAAB for the trial. Soils were freed of extraneous materials: plant roots, weed seeds, and pebbles. The soil samples were then filled into polythene bags of size $25 \times 15 \mathrm{~cm}$ to $2.5 \mathrm{~cm}$ from the brim to allow for watering and placed inside the screen house at the College of Plant Science and Crop Production, FUNAAB.

\section{Experimental design}

The experiment was a factorial in a Completely Randomized Design. There were two factors (nut size (3) and biotype (2) in three replicates which gave a total of 18 treatment units. Twenty five seeds were used for each treatment. A total of 225 seed nuts were used for each biotype.

\section{Seed nut sowing}

Seed nuts were sown at $4-5 \mathrm{~cm}$ depth with concave end upward inside polythene bags and then placed inside screen house and observed daily for emergence. Four hundred and fifty polythene bags were utilized in the study. Each polythene bag was given $30 \mathrm{cl}$ of water daily for 30 days.

\section{Seed quality evaluation}

Data were collected on the following seed quality parameters in both laboratory and screen house.

\section{Laboratory test}

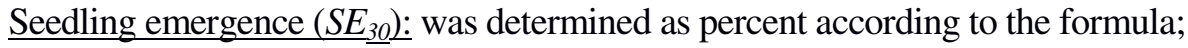

$$
S E_{30}=\frac{N_{S N E 30}}{N_{S N S}} \times 100
$$

where the numbers of emerged seeds $\left(N_{S N E 30}\right)$ and percentage seed nut emergence $\left(N_{S N S}\right)$ were recorded. 
Seedling length $[\mathrm{cm}]$ : This was assessed by measuring the length in centimetres $[\mathrm{cm}]$ from the tip of the cotyledon to the point of radicle emergence with a metric ruler.

Seed width $[\mathrm{cm}]$ : This was determined using a vernier caliper by measuring the width in centimeters.

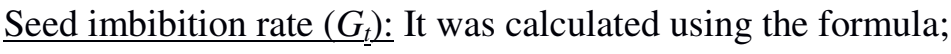

$$
G_{t}=\sum \frac{G_{t}}{T_{t}}
$$

where Gt means germination percentage at $\mathrm{t}^{\text {th }}$ day and $T t$ - a day of germination test

Seed nut weight: Weight of 100 seeds was determined for each genotype in three replicates using sensitive scale.

\section{Screen house test}

Seedling Emergence $\left(S E_{10}\right)$ : Seedling emergence [\%] was determined after 10 days according to the equation of ISTA (1995);

$$
S E_{10}=\frac{N_{S E 10}}{N_{S P}} \times 100
$$

where the number of seedlings emerged at $10^{\text {th }}$ day $\left(N_{S E 10}\right)$ and number of seeds planted $\left(N_{S P}\right)$ were recorded

Seedling shoot length $[\mathrm{cm}]$ : This was assessed by measuring the length of 10 randomly selected seedlings in centimeters $(\mathrm{cm})$ from the tip of the cotyledon to the point of radicle emergence with a metric ruler at the $20^{\text {th }}$ day of emergence.

Seedling Vigour Index (SVI) [\%]: This was determined by multiplying percentage seed germination by the average of seedling length after germination and divided by 100 (Kim et al., 2002; Adebisi, 2004).

Number of leaves per seedling: At the $20^{\text {th }}$ day, 10 seedling leaves were counted from each replicate and the average computed.

Seedling height [\%]: The heights of 10 randomly selected emerging plants were measured 20 days after emergence in centimeter.

Seedling fresh weight [g]: This was determined by weighing 10 randomly selected seedlings in grams at 20 days after emergence.

Seedling dry weight [g]: This was measured using 10 randomly selected seedlings using oven dry method at $130^{\circ} \mathrm{C}$ for one hour at 20 days after emergence.

Seedling growth rate $\left(S_{G R}\right)$ : This was calculated as:

$$
S_{G R}=\frac{\left(W_{2}-W_{1}\right)}{\left(t_{2}-t_{1}\right)}
$$


where $W_{2}$ - seedling fresh weight at final evaluation, $W_{1}$ - seedling fresh weight at first evaluation, $t_{1}$ - time of first evaluation (in days) and $t_{2}$ - time of final evaluation (in days)

\section{Data Analysis:}

Values from seedling emergence percentage were transformed using arcsine transformation prior to analysis. Analysis of variance was carried out on data obtained on laboratory and screen house seed quality determined parameters. Tukey's HSD test at $5 \%$ probability level was used to separate significant treatment means.

\section{RESULTS AND DISCUSSION}

The result from ANOVA (Table 1) shows that the varietal effect was highly significant in respect of seed length, seed width, seed imbibition rate and 100 seed weight. The nut size effect was highly significant $(\mathrm{P} \leq 0.01)$ on seedling length, seed width, seed imbibition rate and 100- seed weight parameters. Similarly, interaction of biotype and nut size effect was highly significant $(\mathrm{P} \leq 0.01)$ on all the four laboratory determined parameters. The significant effect of biotype on all the laboratory determined parameters indicates that selection is possible between the two cashew biotypes for superior seed characters examined. The significant differences recorded among the three nuts sizes of cashew showed that the seed characters varied with nut size. Therefore, it is possible to select for nut size with superior seed characters. The significant interaction of biotype and nut size on 100- seed weight revealed that the variation in the two cashew nut biotypes was influenced by the nut sizes.

Table 1

Mean square values generated from ANOVA for the effect of nut size on seed characters determined in the laboratory

\begin{tabular}{lccccc}
\hline \multicolumn{1}{c}{ Source } & Df & $\begin{array}{c}\text { Seedling length } \\
{[\mathrm{cm}]}\end{array}$ & $\begin{array}{c}\text { Seed width } \\
{[\mathrm{cm}]}\end{array}$ & $\begin{array}{c}\text { Seed Imbibition rate } \\
{[\%]}\end{array}$ & $\begin{array}{c}100 \text { seed weight } \\
{[\mathrm{g}]}\end{array}$ \\
\hline Replicate & 2 & 0.027 & $0.102^{* *}$ & 73.167 & 0.010 \\
Biotype & 1 & $1.620^{* *}$ & $1.445^{* *}$ & $2312.00^{* *}$ & $2.554^{* *}$ \\
Nut size & 2 & $1.365^{* *}$ & $0.455^{* *}$ & $446.00^{* *}$ & $0.080^{* *}$ \\
Nut size *biotype & 2 & $1.045^{* *}$ & $0.185^{* *}$ & $418.20^{* *}$ & $0.010^{* *}$ \\
Error & 10 & 0.119 & 0.014 & 90.567 & 0.008 \\
\hline
\end{tabular}

*Significant at $0.05 \%$ level; **Significant at $0.01 \%$ level

From the data presented in Table 2, the result shows that biotype effect was highly significant $(\mathrm{P} \leq 0.01)$ on seedling fresh weight, seedling dry weight and seedling growth rate but not significant on seedling emergence, seedling length, 
seedling vigour index and number of leaves per stand. The nut size effect was highly significant $(\mathrm{P} \leq 0.01)$ on seedling emergence, seedling vigour index, seedling fresh weight, and seedling growth rate but significant $(\mathrm{P} \leq 0.05)$ on seedling length, number of leaves per plant and seedling dry weight. The result further showed that the interaction effect of cashew biotype and nut size was highly significant on seed germination, seedling fresh weight and seedling growth rate but had significant effect on seedling vigour index. Conversely, the interaction effect was not significant on seedling length, number of leaves per plant and seedling dry weight. The significant effect of biotype effect on seedling fresh weight, dry weight and seedling growth rate suggests that there is possibility to select for biotype with superior seedling growth characters. Similarly, the significant nut size effect on seedling emergence, seedling vigour index, seedling fresh weight and seedling growth rate implies that there is opportunity for selection for nut size with superior seed physiological quality. The significant interaction effect of nut size and biotype recorded on seed weight, seedling vigour index, seedling fresh weight, seedling growth rate and seedling emergence indicates that the differences in seed sizes were responsible for the variation observed between the two biotypes. Significant differences had earlier been reported among seed sizes in different varieties of crop species (Onyeka, 2010; Adebisi et al., 2013, Oyewumi, 2014).

Mean square values generated from ANOVA for the effect of nut size on seed

Table 2 physiological characters of cashew determined in the screen house

\begin{tabular}{lccccccc}
\hline Source & $\begin{array}{c}\text { Seedling } \\
\text { emergence } \\
{[\%]}\end{array}$ & $\begin{array}{c}\text { Seedling length } \\
{[\mathrm{cm}]}\end{array}$ & $\begin{array}{c}\text { Seedling } \\
\text { vigour } \\
\text { index }\end{array}$ & $\begin{array}{c}\text { No. of leaves } \\
\text { per plant }\end{array}$ & $\begin{array}{c}\text { Seedling fresh } \\
\text { weight } \\
{[\mathrm{g}]}\end{array}$ & $\begin{array}{c}\text { Seedling dry } \\
\text { weight } \\
{[\mathrm{g}]}\end{array}$ & $\begin{array}{c}\text { Seedling } \\
\text { growth rate } \\
{\left[\mathrm{g} \times \text { day }^{-1}\right]}\end{array}$ \\
\hline Replicate & 8.234 & 0.523 & 0.124 & 0.389 & 2.549 & 1.757 & 0.345 \\
Biotype (B) & 25.00 & 0.106 & 0.115 & 2.00 & $38.167^{* *}$ & $34.141^{* *}$ & $6.576^{* *}$ \\
Nut size (N) & $1524^{* *}$ & 0.339 & $8.236^{* *}$ & 0.056 & $6.645^{* *}$ & 2.603 & $5.357^{* *}$ \\
$\mathrm{~B} * \mathrm{~N}$ & $2008^{* *}$ & 2.006 & $7.509^{*}$ & 0.500 & $3.846^{* *}$ & 1.730 & $5.354^{* *}$ \\
Error & 211.66 & 0.550 & 1.206 & 0.456 & 0.653 & 1.279 & 0.598 \\
\hline
\end{tabular}

*Significant at $0.05 \%$ level; **Significant at $0.01 \%$ level

Data display in Fig. 1 shows the effect of cashew biotype on laboratory seed characters of cashew. The data indicated that Brazilian biotype gave higher seed length, seed width and 100- seed weight whereas local biotype recorded higher seed imbibitions rate. The superiority of Brazilian biotype over the local biotype in respect of seed length, seed width and 100- seed weight was 24, 21 and $65 \%$ respectively. In a similar vein, seed imbibition rate of local biotype was $4 \%$ greater than Brazilian biotype. The result further shows that Brazilian biotype was 25,31 and $41 \%$ higher in terms of number of leaves per plant, seedling fresh and dry weight respectively over local biotype. 

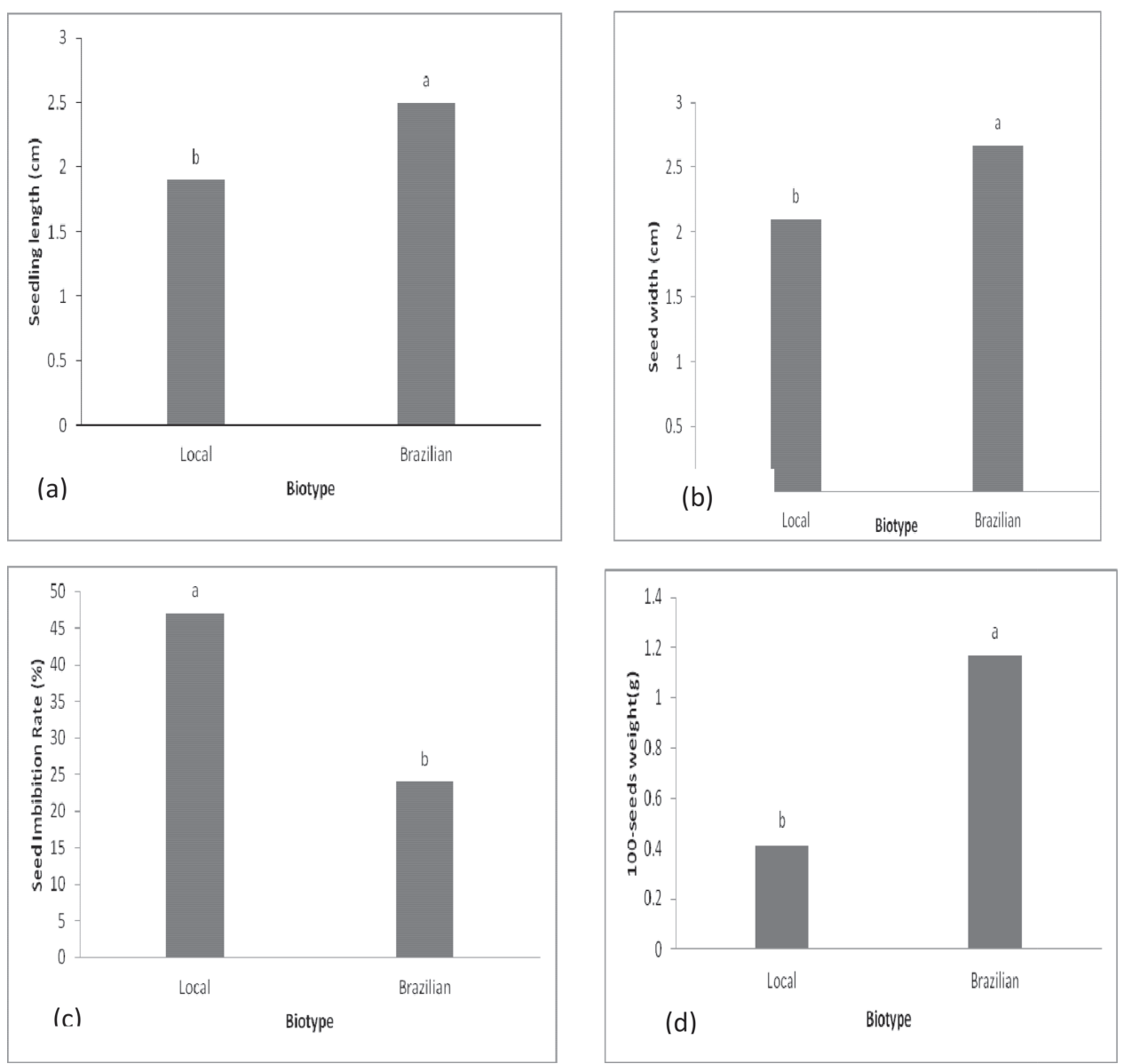

Fig. 1(a-d): Main effect of biotype on seed physical characters of cashew determined in the laboratory

In Fig. 2, the effect of nut size revealed that large nut size recorded the highest seed length whereas small and medium sizes had statistically similar seed length. The seed width of different nut sizes shows that large seed size recorded the largest width $(2.60 \mathrm{~cm})$ followed by the medium nut size while the least was obtained with the small size. On the seed imbibition rate, the highest value was obtained with the large size (45\%) while other sizes had statistically similar imbibitions rate. The large nut size recorded the highest 100 nut weight (0.90) while the other two sizes had statistically similar 100- nut weight. Large nut size was 20 to $35 \%, 9$ to $21 \% 24-38 \%$ and 11 to $16 \%$ superior in seed length, seed width, seed imbibition rate and 100 seed weight respectively over medium and small sizes. 

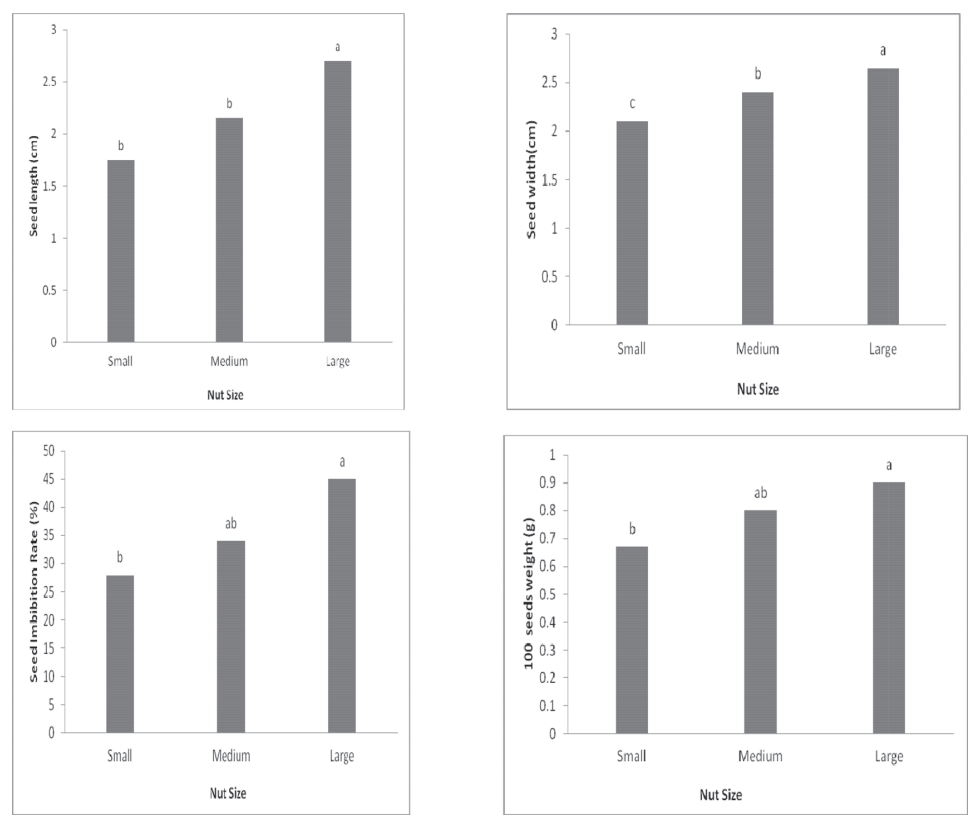

Fig. 2. Main effect of nut size on seed physical characters of cashew determined in the laboratory

Figs. 3 and 4 presents data on main effect of nut size and biotype on screen house physiological characters of cashew. The results revealed that seedling length, seed germination, and seedling vigour index values were statistically similar between the two cashew biotypes. In contrary, Brazilian biotype recorded higher number of leaves per plant, seedling fresh weight and seedling dry weight but lower seedling growth rate compared to local biotype. On the effect of nut size, medium size gave the highest seedling emergence (85\%) compared to values obtained with small and large nut sizes. This supports earlier findings by Adeyemi et al., (2011) who reported that percentage germination was higher in medium cashew nut than jumbo size. The three nut sizes had statistically similar seedling length, number of leaves per plant and seedling dry weight. Large nuts gave the highest seeding vigour index (5.63) which was statistically similar to values of 4.57 obtained with medium nut size while small nut size had lowest seedling vigour index. Seedling fresh weights of medium and large size were statistically similar and higher than the value recorded for small size. Unexpectedly, small nuts gave highest seedling growth rate followed by medium nuts $(2.203 \mathrm{~g})$ and large nuts $(1.325 \mathrm{~g})$. A closer analysis of the data showed that medium nut size had superior seedling emergence of 16 to $23 \%$ above large and small nut sizes while the seedling vigour values of large nut size was 44 and $18 \%$ superior over small and medium nut sizes respectively. 

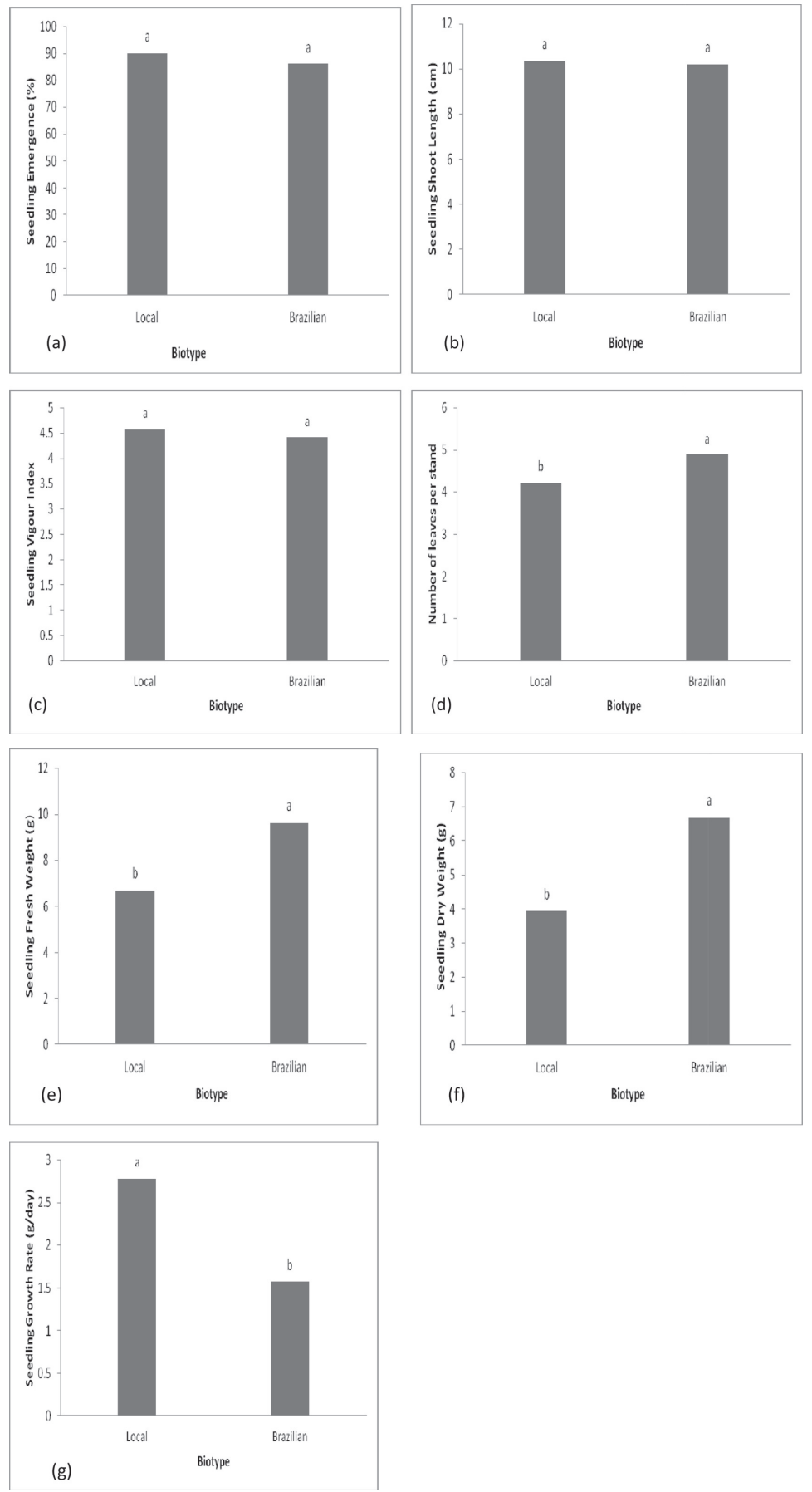

Fig. 3. Main effect of biotype on seed physiological characters of cashew 

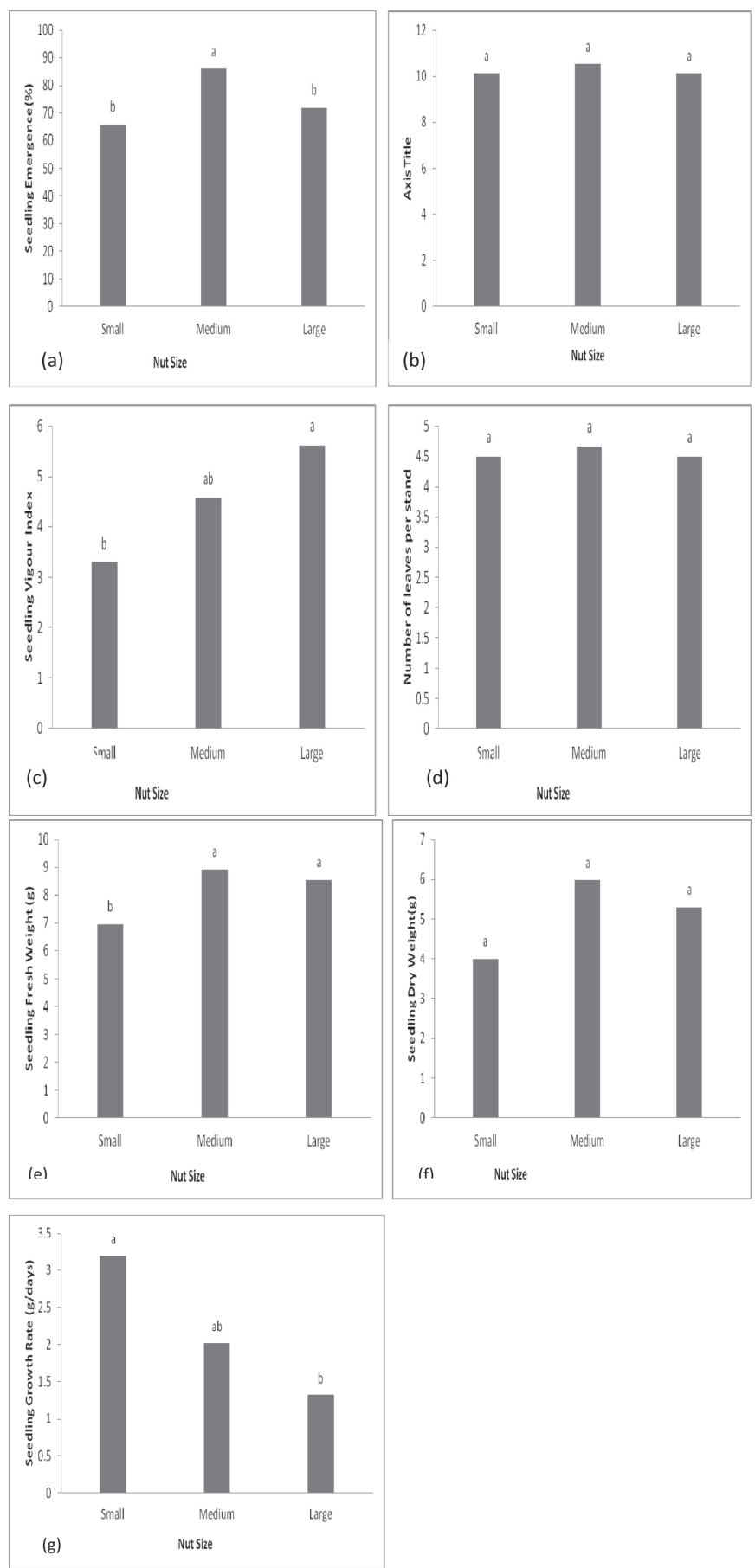

Fig. 4. Main effect of nut size on seed physiological characters of cashew 
Data in Table 3 show that large nuts of Brazilian biotype had the longest nut length $(3.2 \mathrm{~cm})$ while other small nuts of the local biotype recorded the lowest seed length $(1.50 \mathrm{~cm})$ but other treatments combination had statistically similar nut length. Similarly, large nuts of Brazilian biotype had the highest nut width $(3.10 \mathrm{~cm})$ followed by medium nuts of Brazilian biotype with $2.70 \mathrm{~cm}$ while large nuts of local biotype and small nuts of Brazilian biotype recorded the lowest nut width of $2.20 \mathrm{~cm}$ each. In terms of nut imbibition rate, small, medium and large nut sizes of local biotype had the highest seed imbibition rate of between 43 and 50\% though not statistically different from values obtained from large nut of Brazilian biotype (40\%). Seed weight values were variable among treatments combination.

Table 3.

Values of interactive effect of cashew nut size and biotype on seed characters determined in the laboratory

\begin{tabular}{|c|c|c|c|c|c|}
\hline Nut Size & Biotype & $\begin{array}{l}\text { Nut length } \\
{[\mathrm{cm}]}\end{array}$ & $\begin{array}{l}\text { Nut width } \\
{[\mathrm{cm}]}\end{array}$ & $\begin{array}{c}\text { Nut imbibition } \\
\text { rate } \\
{[\%]}\end{array}$ & $\begin{array}{c}100 \text { - seed weight } \\
{[\mathrm{g}]}\end{array}$ \\
\hline \multirow{2}{*}{ Small } & Local & $1.50^{\mathrm{c}}$ & $2.00^{\mathrm{d}}$ & $48^{\mathrm{a}}$ & $0.34^{\mathrm{b}}$ \\
\hline & Brazilian & $2.00^{\mathrm{b}}$ & $2.20^{\mathrm{c}}$ & $20^{\mathrm{b}}$ & $1.00^{\mathrm{a}}$ \\
\hline \multirow{2}{*}{ Medium } & Local & $1.90^{\mathrm{b}}$ & $2.10^{\mathrm{cd}}$ & $43^{\mathrm{a}}$ & $0.40^{\mathrm{b}}$ \\
\hline & Brazilian & $2.40^{\mathrm{b}}$ & $2.70^{\mathrm{b}}$ & $13^{\mathrm{b}}$ & $1.20^{\mathrm{a}}$ \\
\hline \multirow{2}{*}{ Large } & Local & $2.30^{\mathrm{b}}$ & $2.20^{\mathrm{c}}$ & $50^{\mathrm{a}}$ & $0.50^{\mathrm{b}}$ \\
\hline & Brazilian & $3.20^{\mathrm{a}}$ & $3.10^{\mathrm{a}}$ & $40^{\mathrm{a}}$ & $1.30^{\mathrm{a}}$ \\
\hline \multicolumn{2}{|c|}{ Mean SE } & 0.20 & 0.07 & 5.49 & 0.53 \\
\hline
\end{tabular}

SE- Standard Error; Means followed by the same alphabet along the column are not significantly different from one another at $5 \%$ probability level

In Table 4, the result shows that the large nuts of local biotype had the highest seedling emergence ( $92 \%$ ) but other treatment combinations had statistically similar emergence while the lowest emergence was obtained with small nuts of local biotype (42\%). Large nuts of local biotype recorded 9-50\% higher seedling emergence over other treatments. In terms of seedling shoot length, medium and large nuts of Brazil biotype and small nuts of local biotype recorded distinct higher values of above $10 \mathrm{~cm}$ though the values were not statistically different from the values obtained with medium and large nuts of local biotype. The lowest seedling shoot length of $9.39 \mathrm{~cm}$ was obtained with small nuts of Brazilian biotype. On seedling vigour index, large nuts of local biotype had the highest vigour index (6.92) while other treatments had statistically similar vigour index except small nuts of local biotype which recorded the lowest value (2.38). 
Values of interactive effect of cashew nut size and biotype determined in the screen house on seedling emergence, seedling shoot length and seedling vigour index

\begin{tabular}{llccc}
\hline \multirow{2}{*}{ Nut Size } & Biotype & $\begin{array}{c}\text { Seedling emergence } \\
{[\%]}\end{array}$ & $\begin{array}{c}\text { Seedling length } \\
{[\mathrm{cm}]}\end{array}$ & $\begin{array}{c}\text { Seedling Vigour } \\
\text { Index }\end{array}$ \\
\hline \multirow{2}{*}{ Small } & Local & $42^{\mathrm{c}}$ & $10.87^{\mathrm{a}}$ & $2.38^{\mathrm{c}}$ \\
& Brazilian & $86^{\mathrm{b}}$ & $9.39^{\mathrm{b}}$ & $4.21^{\mathrm{b}}$ \\
\multirow{2}{*}{ Medium } & Local & $86^{\mathrm{b}}$ & $10.25^{\mathrm{ab}}$ & $4.44^{\mathrm{b}}$ \\
& Brazilian & $86^{\mathrm{b}}$ & $10.83^{\mathrm{a}}$ & $4.70^{\mathrm{b}}$ \\
\multirow{2}{*}{ Large } & Local & $92^{\mathrm{a}}$ & $9.91^{\mathrm{ab}}$ & $6.92^{\mathrm{a}}$ \\
& Brazilian & $84^{\mathrm{b}}$ & $10.35^{\mathrm{a}}$ & $4.34^{\mathrm{b}}$ \\
& & 5.94 & 0.43 & 0.63 \\
\hline
\end{tabular}

Means followed by the same alphabet along the column are not significantly different from one another at $5 \%$ probability level

The result in Table 5 shows that number of leaves per plant of small, medium and larger nuts of Brazilian biotype recorded the highest values of leaves each whereas other treatments had statistically similar values. For seedling fresh weight, medium nuts of Brazilian biotypes had the highest value of $11.29 \mathrm{~g}$ while small and medium nut sizes of local biotype recorded lowest values of 6.12 and $6.56 \mathrm{~g}$, respectively. In terms of seedling dry weight, medium nuts of Brazilian biotype had the highest value of $7.95 \mathrm{~g}$ followed by large nuts of Brazilian biotype with $6.50 \mathrm{~g}$ while small nuts of local and Brazilian biotypes and medium nuts of local biotype recorded the lowest values of between $3.60-4.00 \mathrm{~g}$. On the seedling growth rate, small nuts of local biotype had the highest value of $4.89 \mathrm{~g} \times$ day $^{-1}$ while other treatments had statistically similar values of between 1.50 and $2.10 \mathrm{~g} \times$ day.

Values of Interactive effect of nut size and biotype of seedling growth characters of cashew

\begin{tabular}{cccccc}
\hline Nut Size & Biotype & $\begin{array}{c}\text { No. of leaves } \\
\text { per plant }\end{array}$ & $\begin{array}{c}\text { Seedling fresh } \\
\text { weight }[\mathrm{g}]\end{array}$ & $\begin{array}{c}\text { Seedling dry weight } \\
{[\mathrm{g}]}\end{array}$ & $\begin{array}{c}\text { Seedling growth } \\
\text { rate }\left[\mathrm{g} \times \text { day }^{-1}\right]\end{array}$ \\
\hline \multirow{2}{*}{ Small } & Local & $4^{\mathrm{b}}$ & $6.12^{\mathrm{c}}$ & $3.72^{\mathrm{c}}$ & $4.89^{\mathrm{a}}$ \\
& Brazilian & $5^{\mathrm{a}}$ & $7.63^{\mathrm{b}}$ & $3.60^{\mathrm{c}}$ & $1.50^{\mathrm{b}}$ \\
\multirow{2}{*}{ Medium } & Local & $4^{\mathrm{b}}$ & $6.56^{\mathrm{c}}$ & $4.00^{\mathrm{c}}$ & $2.10^{\mathrm{b}}$ \\
& Brazilian & $5^{\mathrm{a}}$ & $11.29^{\mathrm{a}}$ & $7.95^{\mathrm{a}}$ & $1.95^{\mathrm{b}}$ \\
\multirow{2}{*}{ Large } & Local & $4^{\mathrm{b}}$ & $7.32^{\mathrm{b}}$ & $4.07^{\mathrm{c}}$ & $1.37^{\mathrm{b}}$ \\
& Brazilian & $5^{\mathrm{a}}$ & $7.78^{\mathrm{b}}$ & $6.50^{\mathrm{b}}$ & $1.28^{\mathrm{b}}$ \\
\hline
\end{tabular}

Means followed by the same alphabet along the column are not different from one another at $5 \%$ probability level 


\section{CONCLUSION}

Significant differences were observed between the two biotypes for all seed metric and physiological characters evaluated. Differences in the nut sizes influenced all the seed quality parameters observed in this study. Large nut size of Brazilian biotype had the best seed metric characteristics. Large seed nuts of local biotype showed the highest seedling emergence and seedling vigour index. Medium nuts of the two biotypes of cashew were found with superior seedling emergence, seedling vigour index and growth characters and therefore recommended in cashew multiplication.

Use of seed invigoration treatments that will enhance seedling emergence and seedling growth parameters in the three nut sizes are necessary and therefore advocated. However, information on physiology of the seed nuts of cashew under ambient humid conditions in Southwestern Nigeria is lacking and therefore advocated for further research.

\section{REFERENCES}

Adebisi, M.A. 2004. Variation, stability and correlation studies in seed quality and yield of sesame (Sesamum Indicum L.). PhD thesis. Department of Plant Breeding and Seed Technology, Federal University of Agriculture, Abeokuta, Ogun State, Nigeria. $132 \mathrm{pp}$.

Adeyemi, E. A., Tijani-Eniola, H. and Famaye, A. O. 2011. Nut Storage Periods and Nut Sizes Effects on Cashew (Anacardium Occidentale L.) Seedling Emergence and Growth. ARPN Journal of Agricultural and Biological Science 6 (7):33-38

Auckland, A.K. 1961. The influence of seed quality on the early growth of cashew. Tropical Agriculture, Trinidad, 38, 57-67.

Ayfer, M. and Serr, E.F 1961. Effects of gibberellin and other factors on seed germination and early growth in Pistacia species. Proceedings of the American Society for Horticultural Science, 77, 308-315.

FAO. 2004. Food and Agriculture Organization, Online Production Statistics Division.

FAO. 2007. Food and Agriculture Organization, Online Production Statistics Division.

Ibikunle, B.O and Komolafe, D.A 1973. Some experiments on the germination of cashew nuts (Anacardium occidentale Linn.). Nigerian Journal of Science, 7, 19-29.

Kim, S. H, Choe, Z. R., Kang, J. H., Copeland, L. O. and Elias, S. G. 2002. Multiple seed vigour indices to predict field emergence and performance of barley. Seed Science and Technology 22:29-38.

Onyeka, C. V. 2010. Studies on effect of storage duration, nut size and water soaking time on seed germination and early seedling vigour in cashew. Project Report. Department of Plant Breeding and Seed Technology, Federal University of Agriculture, Abeokuta, Ogun State, Nigeria. 30 pp.

Oyewumi, A. A. 2014. Response of nut quality to storage period and nut size in two cashew (Anacardium occidentale Linn.) biotypes. Master of Agriculture dissertation, Department of Plant Breeding and Seed Technology, Federal University of Agriculture, Abeokuta, Ogun State, South West, Nigeria 83pp.

Subbaiah, C.C. 1982. Effect of pre-soaking in organic solvents on seed germination and seedling growth of cashew. Scientia Horticulturae, 18, 137-142.

Turner, D.J. 1956. Some observations on the germination and grading of cashew nut. East African Agricultural Journal, 22, 35-39

Udoh, D.J, Ndoh, B.A, Asuquo, P.E and Ndaeyo, N.U. 2005. Crop Production Techniques for the Tropics. Concept Publication (Nig.) Ltd, 464pp

Vertucci, C. N. 1989. The kinetics of seed imbibition. Seed Science and Technology, 16:601-612. 